\title{
Narratives of grassroots innovations: a comparison of voluntary simplicity and the transition movement in Italy
}

Article

Accepted Version

Feola, G. (2014) Narratives of grassroots innovations: a comparison of voluntary simplicity and the transition movement in Italy. International Journal of Innovation and Sustainable Development, 8 (3). pp. 250-269. ISSN 1740-8822 doi: https://doi.org/10.1504/IJISD.2014.066612 Available at https://centaur.reading.ac.uk/38980/

It is advisable to refer to the publisher's version if you intend to cite from the work. See Guidance on citing.

Published version at: http://www.inderscience.com/info/inarticle.php?artid=66612

To link to this article DOI: http://dx.doi.org/10.1504/IJISD.2014.066612

Publisher: Inderscience Publishers

All outputs in CentAUR are protected by Intellectual Property Rights law, including copyright law. Copyright and IPR is retained by the creators or other copyright holders. Terms and conditions for use of this material are defined in the End User Agreement.

www.reading.ac.uk/centaur 
Central Archive at the University of Reading

Reading's research outputs online 


\title{
Narratives of grassroots innovations: A comparison of Voluntary Simplicity and the Transition Movement in Italy
}

\section{Giuseppe Feola}

Department of Geography and Environmental Science, University of Reading, Whiteknights - PO Box 227 , RG66AB Reading, United Kingdom email: g.feola@reading.ac.uk telephone number: 00441183787496

\begin{abstract}
Grassroots innovations (GI) are promising examples of deliberate transformation of sociotechnical systems towards resilience and sustainability. However, evidence is needed on the factors that limit or enable their success. This paper set out to study how GI use narratives to empower innovation in the face of incumbent socio-technical regimes. Institutional documents were comparatively analyzed to assess how the narratives influence the structure, form of action and external interactions of two Italian grassroots networks, Bilanci di Giustizia and Transition Network Italy. The paper finds an internal consistency between narratives and strategies for each of the two networks. The paper also highlights core similarities, but also significant differences in the ethical basis of the two narratives, and in the organizations and strategies. Such differences determine different forms of innovation empowerment and expose the niche to different potentials to transform incumbent regimes, or to the risk of being co-opted by them.
\end{abstract}

Keywords: grassroots innovation; transition movement; voluntary simplicity; narrative; Italy

Biographycal statement: Giuseppe Feola is Lecturer in Environment and Developement in the Department of Geography and Environmental Science at the University of Reading, United Kingdom. 


\section{$1 \quad 1$ Introduction}

There is a growing interest among researchers and policy-makers in transformational

3 social change as a way to address environmental change (e.g. O’Brien, 2011; WBGU, 2011;

4 Wiek et al, 2012; IPCC, 2013). That is, in proactive action that deliberately aims to

5 restructure coupled socio-technical and environmental systems and shape their coevolution

6 towards sustainable pathways.

Grassroots innovations (GI) are one of the most interesting examples of such deliberate

8 change. Following Seyfang and Smith (2007), GI can be defined as "networks of activists and

9 organizations generating novel bottom-up solutions for sustainable development; solutions

10 that respond to the local situation and the interests and values of the communities involved"

11 (ibid, page 585). GI distinguish themselves from mainstream green business by operating

12 from the bottom-up, in civil society arenas, experimenting with often radical social and

13 technological innovation, and by developing new systems of provisions that reflect

14 alternative worldviews and systems of values (Dahle, 2007; Seyfang and Smith, 2007;

15 Seyfang et al, 2010). GI are motivated by a vision of active citizenship, whereby citizens,

16 often organised at community or neighbourhood level, have a chance to influence society

17 directly and ethically, and to exert control over their own lives, while at the same time having

18 responsible impact on the world (Ruggiero, 2000; Kennedy, 2011). GI represent "a

19 fascinating social experiment" of innovative technologies, values and institutions (Haxeltine

20 and Seyfang, 2009, page 16), and can be seen as incubators of post-growth alternatives to the

21 present capitalist and neo-liberal model of societal development (Seyfang 2001; Seyfang and

22 Smith, 2007; Haxeltine and Seyfang, 2009; Martinez-Alier et al, 2010).

23 However, while the literature offers many positive accounts of particular local 24 examples, more critical views on GI have recently emerged. It has been argued that the 
1 "research base evaluating community-based carbon initiatives is limited in scope and depth"

2 (Walker, 2011, page 779), and that little evidence exists on scaling-up and replication

3 (Bergman et al, 2010; Walker, 2011). There is therefore a need for better understanding "the

4 internal dynamics and external factors that limit and enable [GI's] success" (Mulugetta et al,

5 2011, page 7544; see also Seyfang and Smith, 2007; Scott-Cato and Hillier, 2010; Walker,

6 2011).

Literature shows that one such factor is the narrative developed by the GI (e.g. Brown

8 and Rhodes, 2005; Smith et al, 2005; Smith, 2011). Narratives play an essential role in sense-

9 making, communication, learning and identification (Brown and Rhodes, 2005), and,

10 therefore, mediate the community's internal structure, form of action and its interaction with

11 other actors. Little evidence exists so far on how these three aspects are shaped by the GI

12 themselves through narratives. Moreover, it is the working hypothesis of this study that

13 distinct GI may elaborate different narratives, which in turn influence their internal and

14 external dynamics differently. A comparative analysis can, therefore, shed light on the role

15 played by narratives by tracing their influence on the GI's structure, form of action and

16 interaction with other actors, and help understand how narratives contribute to determine

17 different forms of innovation empowerment.

This paper sets out to compare two GI and is focussed on how the narratives

19 respectively influence the internal GI's structure, form of action, and interactions with other

20 actors (e.g. potential members, other GIs, local authorities and businesses). It does not,

21 however, focuse on how the GI's narrative influences, e.g. transforms, the external context

22 and, due to its cross-sectional nature, does not focuse on how the GI's narrative has

23 influenced their development over time. With reference to two distinct Italian networks of

24 diverse grassroots initiatives, the paper sets out to answer the following questions: 
$1 \quad$ 1. Can different narratives be identified?

2 2. In what ways are narratives different or similar?

3 3. How do these narratives influence the GI's internal structure, form of action, and

4 interactions with the other actors?

54 What forms of innovation empowerment are determined by the structure, form of

6 action, and interactions with the other actors as informed by the respective narratives?

7 The paper is structured as follows. Firstly, the grassroots innovation framework is

8 outlined. This forms the basis for the second section of the paper, which makes the case for

9 the key role of narratives for the GI as innovative niches. Thirdly, two distinct GI active in

10 Italy are described and analysed as case studies. Their narratives are then dissected and

11 compared. Finally, the paper concludes with a reflection on the role of narratives for the GI's

12 ability to empower innovation towards resilience and sustainability, and identifies avenues for

13 further research.

152 Grassroots innovations as innovative niches

16 Grassroots action towards sustainability or resilience has been framed in different

17 ways in the literature, including as social innovation and social movement organizations (e.g.

18 Moulaert et al, 2005; Seyfang et al, 2010; Hagreaves et al, 2011). However, a more recently

19 proposed framework is that of grassroots innovation which has the significant advantage of

20 bridging the innovation and community action strands of literature, thus providing a nuanced

21 and multi-layered theoretical approach to grassroots action towards sustainability (Seyfang

22 and Smith, 2007; Seyfang and Haxeltine, 2012) ${ }^{1}$. In this multilevel framework, GI are 
Feola, G. 2014. Narratives of grassroots innovations: A comparison of Voluntary Simplicity and the Transition Movement in Italy. International Journal of Innovation and Sustainable Development, 8(3):250-269. DOI: 10.1504/IJISD.2014.066612

1 conceptualised as niches, which are spaces of innovation where the actors explore and

2 experiment with new technologies and practices that diverge from the mainstream or status

3 quo (Rotmans et al, 2001; Smith and Raven, 2012). Niches are spaces where integrated sets

4 of technologies and practices that deviate from the socio-technical regime, i.e. dominant

5 practices, rules and shared assumptions, can be reconfigured (Smith et al, 2005; Hargreaves

6 et al, 2011). Niches act as incubators or protective spaces that shield innovation from

7 selecting pressures, nurture them and empower them to compete with, or transform, the

8 regime (Smith and Raven, 2012). They can take the form of shadow (i.e. informal) or

9 canonical (i.e. formal, registered organizations) systems (Pelling et al, 2007). While niches

10 may grow and attract interest from the socio-technical regime, niches alone do not usually

11 trigger wider change (Schot and Geels, 2008). In fact, change in the socio-technical regime

12 also strongly depends on broader landscape dynamics, which include material infrastructure,

13 worldviews and paradigms, the macro economy, demography and the natural environment

14 (Rotmans et al, 2001). The trajectory of change, as well as its likelihood, intensity and

15 duration, is therefore a result of the interactions occurring across three levels, i.e. micro

16 (niches), meso (regime) and macro (landscape) (Rotmans et al, 2001; Geels and Schot, 2007),

17 which determine the "opportunity structure" for the niche to bring about change (Sztompka,

18 1993). In sum, it is on the interaction among innovative niches, regime and landscape that the

19 transition pathway emerges, i.e. stability, top-down reform, weak co-option, innovative

20 substitution, innovative competition (Geels and Shot, 2007; Schot and Geels, 2008).

Seyfang et al (2010) and Hagreaves et al (2011) provide interesting discussions on how the grassroots innovation framework relates to, and is potentially complemented by, other approaches including transition theory, social practices theory and new social movements theory. 


\section{The use of narratives in innovative niches}

Narratives are a form of discourse. They "concern chains of events and/or actions -

4 perhaps partially teleologically linked, leading to a conclusion (i.e. outcome) that is not

5 predictable as a consequence of the interposition of a multitude of contingent events" (Abell,

6 2004:289). They comprise three essential elements, i.e. world states, actors and actions. A

7 coherent directionality, either positive or negative, can often be identified in narratives (Riley

8 and Hawe, 2005), whereby they often concern some form of transformation of world states

9 (Franzosi, 1998) brought about by actors.

10 Narratives play a role in at least five morphogenetic processes (Sztompka, 1993) in

11 organizations, groups or communities, i.e. i) sensemaking, ii) communication, iii) politics and

12 power, iv) learning and change and v) identity and identification (Brown and Rhodes, 2005).

13 Narratives help to shape a common understanding of the world and of the organization itself;

14 function as frameworks for the construction of reality, in which sequence, meaning and

15 structures are socially defined and reaffirmed; make members' experience meaningful and

16 communicable; support, justify and provide a measure of change; help to establish and

17 maintain collective identity, and collective action (Ruggiero, 2000; Brown and Rhodes,

18 2005). Consequently, narratives facilitate the frame alignment process (Snow et al, 1986), i.e.

19 articulate the worldviews that are mobilised to legitimate the movement's goals and actions.

20 They also help to create and reinforce a common vocabulary, ideas and beliefs shared by the

21 members, thus shaping identity. Because this type of network is not motivated by issues of

22 access to or distribution of material resources, but by the emergence of new systems of values

23 that collide, to some extent, with those prevalent in society, social integration within these

24 movements is possible only if these networks are successful in the production of meaning

25 (Melucci, 1985; Ruggiero, 2000), to which a strong and convincing narrative is functional. 
Narratives have been argued to play a key role also in the interactions between regime

2 and niches. For example, Smith et al (2005) and Rotmans et al (2001) stressed the manifold

3 roles played by expectations and visions in regime transformation: visions and expectations

4 are problem-defining tools because they point out the problems that motivate the need for

5 change, and they serve as a map of the "possibility space" or realm of plausible alternatives

6 to the regime. They constitute the narrative around which the network of actors is built, both

7 inclusively and exclusively, set the identity landmarks around which communities of practice

8 and interest coalesce into coalitions for change, and are employed in attracting resources

9 (Smith et al, 2005). The narrative's degree of interpretative flexibility, and its "adaptability to

10 circumstances, can influence the cohesiveness and robustness of the coalition organised

11 through it" (Smith et al, 2005, page 1506). Importantly, narratives are tools employed in the

12 niche to empower the innovation, either in the direction of "fit and conform" to, or of "stretch

13 and transform" a socio-technical regime configuration (Smith and Raven, 2012). In the latter

14 case, narratives help create "a) positive expectations about the future that justify the niche to

15 wider audiences; b) explicit claims for present-day niche friendly institutional reforms; and c)

16 statements that re-frame the past to challenge the current prevailing regime in ways that

17 emphasise future opportunities for the innovation" (Smith and Raven, 2012, page1033).

\section{Method}

Institutional documents (Corbetta, 1999), in print and electronic form, produced by

21 two Italian GI networks, i.e. Bilanci di Giustizia ("Budgets for Justice") and Transition

22 Network Italy, were compared. The documents analysed included institutional reports,

23 handbooks, leaflets, conference proceedings, websites and blogs. These documents had been

24 produced and circulated by the central or regional hubs of each network, labelled by the

25 network logo, and were therefore considered to represent the 'official' perspective of the 
1 network. The documentary analysis aimed to identify similarities and differences in the two

2 networks' narratives. While narrative analysis often tends to stress diversity among members

3 of an organization, group or community (Brown and Rhodes, 2005), the focus of this study

4 was on the coherent narrative that the two GI networks employ to achieve "collective

5 centring" (Boyce, 1996), define the GI's community identity and mark their distinctiveness

6 (Rappaport, 2000; Stuber, 2000). The documentary analysis was complemented by a review

7 of existing studies on the two networks.

The networks selected for this study operated at the national level in Italy and can be

9 considered manifestations of two broader movements, i.e. voluntary simplicity and Transition

10 Network, of which they retain essential characteristics. Studying such more specific GI,

11 rather than their international counterparts, enabled more insightful comparative analysis,

12 which referred to clearly recognisable networks with a strongly defined identity.

\section{Case studies}

Following Alexander (2011, page 186), Voluntary simplicity can be defined as “an

18 oppositional living strategy that rejects the high consumption, materialistic lifestyles of

19 consumer cultures and affirms what is often just called 'the simple life' or 'downshifting'”.

20 Three variations of voluntary simplicity have been identified, i.e. the downshifting, strong

21 simplifying and simple living, corresponding to increasing levels of intensity (Etzioni, 1998).

22 Voluntary simplicity as GI is characterised by networked social actors moved by a sense of

23 responsibility and environmental, ethical and health concerns (Elgin and Mitchell 1977; Shaw

24 and Newholm, 2002). Simple livers affirm, among others, the values of material simplicity,

25 human scale, self-determination, ecological awareness and personal growth (Elgin and 
1 Mitchell, 1977; Etzioni, 1998). These are translated into everyday practices that seek to

2 establish an alternative to consumer culture, including for example self-production of food,

3 recycling and reuse of goods, use of public transport, reduction of the use of an owned car,

4 time banks, reduction of work time, ethical finance and use of alternative currencies. Voluntary simplicity is not a back-to-nature, subsistence life or ascetic movement, and

6 it does not equate with renouncing the advantages of science and technology, or regressing to

7 a primitive state, or becoming a self-righteous puritan (Alexander, 2011). Instead, voluntary

8 simplicity advocates the liberation from the desires induced by consumer culture and a re-

9 appropriation of time and resources for personal development, convivial life, social relations

10 and, in general, a preference for quality over quantity. Thus, in its most complete form,

11 voluntary simplicity requires an holistic lifestyle restructuring, which strongly relates

12 personal (happiness, contentment, satisfaction), social/communitarian (community

13 engagement), humanitarian (world poverty) and ecological lifestyle dimensions (Elgin, 1981;

14 Doherty and Etzioni, 2003; Alexander, 2011), and thereby goes far beyond the limited

15 adoption of single but inconsistent "green", "ethical" or "environmentally friendly" practices.

16 Voluntary simplicity is a highly diverse bottom-up or grassroots movement, which operates in

17 the absence of an official, centralised international organization.

\section{Voluntary simplicity in Italy: Bilanci di Giustizia}

Arguably the most significant GI network of simple livers in Italy is the Bilanci di

21 Giustizia ("Budgets for Justice") campaign (BDG). BDG is a network of families committed

22 to change towards more ethical, sustainable and wellbeing enhancing lifestyles (Gaggioli and

23 Valer, 2011). The families are invited to fill monthly and yearly budgets (provided as

24 spreadsheets), in order to monitor and measure their own consumption in terms of justice,

25 sustainability and quality of life. These budgets are not compulsory, but represent the learning 
Feola, G. 2014. Narratives of grassroots innovations: A comparison of Voluntary Simplicity and the Transition Movement in Italy. International Journal of Innovation and Sustainable Development, 8(3):250-269. DOI: 10.1504/IJISD.2014.066612

1 tool through which families can set targets of lifestyle change or consumption reduction, thus

2 supporting the process of transition to a simpler lifestyle, and its consolidation over time. The

3 transition to a simpler lifestyle takes the form of consumption moved to ethical and

4 sustainable goods and services (qualitative), and of reduction of consumption (quantitative),

5 both of which entail the change of everyday practices towards innovative, convivial, foms of

6 self-production and social interaction. The data collected through the budgets also allow for a

7 comparison with national averages (e.g. as elaborated by the national statistical office), which

8 in turn provides a measure of the change achieved by the campaign (BDG, 2009).

BDG began in 1993 on the occasion of a conference titled "Quando l'economia

10 uccide, bisogna cambiare!" (“When the economy kills, one needs change!") and was

11 organised by a Catholic pacifist association called Beati i costruttori di pace (Gaggioli and

12 Valer, 2011). The conference not only denounced the inequality in the levels of resource

13 consumption and wellbeing in the global North and South, but also called for individual

14 responsibility and adoption of active roles in changing such unequal configurations through

15 ethical consumption and lifestyles (Gaggioli and Valer, 2011).

16 The networked families share their experiences and support each other through local

17 groups. There are neither pre-defined rules according to which local groups operate nor strict

18 membership requirements. Such groups are usually small and can determine the meeting

19 frequency as well as the modalities and activities or topics. The groups are supported by a

20 central secretariat that stimulates the communication among groups, maintains the website

21 (www.bilancidigiustizia.it), interacts with the press and facilitates the annual national meeting

22 of BDG families. This annual meeting is the chance for the networked families to meet

23 nationally and share experiences and practices. The secretariat relies on voluntary work and

24 its activities are partly self-funded by the families. About 1000 families and 30 local groups,

25 mainly in northern and central Italy are currently engaged in BDG (BDG, 2009), though a 
Feola, G. 2014. Narratives of grassroots innovations: A comparison of Voluntary Simplicity and the Transition Movement in Italy. International Journal of Innovation and Sustainable Development, 8(3):250-269. DOI: 10.1504/IJISD.2014.066612

1 precise accounting is made difficult by the non-compulsory nature of the monthly and yearly

2 budget and the consequently fluid nature of the membership of BDG.

\subsection{The Transition Movement}

The Transition Movement (TM) originated in Totnes, Devon (England) in 2006 and

6 originally built on the earlier experience of the permaculturist Rob Hopkins in Kinsale,

7 Ireland, who is also the movement's iconic figure (Hopkins, 2011). The TM is a transnational

8 grassroots social movement that seeks to deal with climate change and shrinking supplies of

9 cheap energy ('peak oil'), which are identified as the "two toughest challenges facing

10 humankind at the start of this 21st century" (Brangwyn and Hopkins, 2008, page 3), through

11 the promotion of an 'energy descent' (Brangwyn and Hopkins, 2008). More recently the

12 financial and economic crisis has been added to the concerns of the TM (Hopkins, 2011).

13 Such a transition is to be achieved through active cooperation in the community, social

14 learning and innovation promoted among all members of society. The capability to respond to

15 external stresses, i.e. to keep functioning and thriving without cheap oil and in the face of

16 climate change, is central for the TM and is referred to as resilience. Resilience is understood

17 to increase social wellbeing (Hopkins, 2011). Thus, peak oil, climate change, and the

18 economic crisis are considered not only challenges, but also opportunities for positive change

19 in the community (Hopkins, 2009). Essential resources for achieving such positive change are

20 the creativity, motivation and knowledge that local communities have the potential to

21 unleash.

A major theme in the TM is that of re-localisation, which implies i) diversification of

23 local economies, ii) reduction of the dependency on unstable global markets and increasingly

24 more expensive transport, iii) willingness to take direct action, and to foster innovation

25 capacity without waiting for national or local political institutions or the business sector to 
Feola, G. 2014. Narratives of grassroots innovations: A comparison of Voluntary Simplicity and the Transition Movement in Italy. International Journal of Innovation and Sustainable Development, 8(3):250-269. DOI: 10.1504/IJISD.2014.066612

1 intervene. Therefore, while the need for action at local, national and international level, as

2 well as in all sectors, i.e. civil society, state authorities and business, is recognised (Hopkins,

3 2011), it is the local community level that constitutes the TM's focus. Transition communities

4 usually address a rather definite set of themes, among which food, transport, energy and local

5 currencies are the most frequent (Hopkins, 2011), but they do it in a diverse and locally

6 specific manner.

The TM has developed in time a set of guidelines among which a Transition

8 Handbook (Hopkins, 2009), a Transition Initiatives Primer (Brangwyn and Hopkins, 2008)

9 and Transition Companion (Hopkins, 2011). Several other thematic resources concerning, for

10 example, food self-production or homes, have also been produced. The transition model

11 (Brangwyn and Hopkins, 2008) is a set of 12 steps that communities can follow to set up a

12 local transition initiative and make it thrive. They were recently re-elaborated in the " 5

13 ingredients" of transition, i.e. i) starting-out, ii) deepening, iii) connecting, iv) building, v)

14 daring to dream (Hopkins, 2011). A growingly important part of the transition process is the

15 'inner transition' which couples personal change to external one. Communities can adapt

16 these steps to their specific case, and therefore they do not need to make up a compulsory list.

17 However, these 12 steps set a clear path of actions that communities should follow to develop

18 successful transition initiatives.

The TM has also developed a rather formal organizational structure, the Transition

20 Network (www.transitionnetwork.org), made of local transition initiatives, regional and

21 national hubs, while the central point of reference is the Transition initiatives in Totnes. This

22 structure develops the grand narrative and respective documentation, and produces the above

23 mentioned guidelines, but also delivers training for transitioners, consultancy services,

24 facilitation of information exchange and learning among local initiatives. Importantly, the

25 network also established a system of branding, according to which communities that desire to 
1 be recognised as "official" members of the network need to comply with a set of criteria such

2 as having attended a training session, having drafted and approved a constitution, be

3 composed of at least $4 / 5$ people and demonstrate commitment to network with others,

4 including local and national authorities. Local transition initiatives that are inspired by the

5 TM principles but that do not comply with these criteria are listed as 'muller'. As of June

6 2012, there were approximately 421 official and 566 mulling initiatives in 34 countries

7 worldwide (www.transitionnetwork.org).

8

11 (http://transitionitalia.wordpress.com/), is the Italian national hub and an official part of the

12 TM. The TMI has all the defining features of the TM, including narrative, strategy and

13 organization. TMI aims to be a light organization that facilitates local transition initiatives in

14 Italy, maintains relationships with the international network and provides documentation,

15 training and support to local transition initiatives. Most of the key documentation materials

16 made available by the TMI were translated from the English version, i.e. originally produced

17 or diffused by the TM. The production of original materials by the TMI has been limited

18 mainly to informal media such as blog posts or interviews, and minor brochures. The TMI

19 also organises training, information events, talks, seminars and visits to other transition

20 initiatives. As of August 2012, there were 24 official and 52 mulling initiatives in Italy

21 (http://transitionitalia.wordpress.com).

22

\section{The comparison of narratives}

This section summarizes the two GIs' narratives in the three elements of i) world

25 states, ii) actors, iii) actions (Abell, 2004). In so doing, it illustrates how the narratives 
1 underpin not only the GI's identity, but their structures, form of action and interactions with

2 other actors (Table 1).

[Table 1 here]

\section{$5 \quad 6.1$ World states}

\section{Environmental crisis and social wellbeing}

Both BDG and TMI start from a critique of the environmental unsustainability caused

8 by an economic system that undermines its very physical and natural basis. By and large, this

9 is understood to be the result of the way in which economic actors, government and citizens

10 and consumers have interacted in economic and political arenas, producing and reinforcing

11 norms, technologies, institutions and practices that create high levels of material

12 consumption. Whether emphasising climate change and depletion of fossil fuels (TMI, see

13 Chamberlin, 2009; Hopkins, 2011) or more general environmental degradation and depletion

14 of non-renewable natural resources (BDG, see Bologna et al, 2000), both BDG and TMI point

15 to the need to transform current socio-technical regimes embedded in an environmentally

16 unsustainable model of development.

17 In addition to the environmental crisis, the inability of the current model of

18 development to satisfy the need for full human development and happiness (Jackson, 2009),

19 is a persistent theme in both narratives. The current regime is understood as unable to meet

20 the basic social needs (Hopkins, 2011). Instead, it is perceived as largely based on the

21 continuous creation of desires that fuel dissatisfaction (Gesualdi, 2009; Gaggioli and Valer,

22 2011). Both BDG and TMI see in the current financial and economic crisis an exacerbation

23 and sign of crisis of such model of development (Gesualdi, 2009; Hopkins, 2011). 
The TMI's narrative departs from the two challenges of peak oil and climate change,

2 and focuses on Italy, and more generally on industrialised countries, which caused, and suffer

3 from these two environmental challenges. While the financial and economic crisis is

4 increasingly gaining importance in TMI's narrative together with local economic resilience,

5 this does not include an analysis of the structural relationship between industrialised and poor

6 countries, which is an element of BDG's narrative. The latter, in fact, builds strongly upon the

7 North-South relationship by linking levels of overconsumption in industrialised countries and

8 of underdevelopment in poor countries, whereby the former is possible only at the expense of

9 the latter (Gesualdi, 2009). Material consumption represents the key link between

10 environmental degradation and poor quality of life in the North, and underdevelopment in the

11 South (Gesualdi, 2009). Importantly, by structurally incorporating the unequal distribution of

12 resource consumption and benefits, BDG's narrative places the issue of global intra-

13 generational justice at the centre of the movement's legitimation and call for societal change

14 (Gaggioli and Valer, 2011). The fact that the word "justice" is part of this GI's name just

15 stresses this issue's importance for this network.

16

\section{Resilience and sustainability}

The different importance given to the issues of global justice is strongly related to the different keywords used by BDG and TMI, i.e. resilience and sustainability. These keywords signal two different traditions of thought from which TMI and BDG respectively draw. The TMI's narrative is strongly based on resilience theory (Gunderson and Holling, 2001) and system thinking, the latter being represented in the TMI's literature by various strands of scholarship including permaculture (e.g. Holmgren, 2004), system dynamics (e.g. Meadows

et al, 2005) and system self-organiation (Maturana and Varela, 1992) (Hopkins, 2011). It has

been noted how these traditions tend to overlook issues of power and justice (Pelling, 2011). 
1 Consistently, TMI takes an explicitly apolitical and non-confrontational stand that is

2 formalised in each official local initiative's founding charter (Brangwyn and Hopkins, 2008).

3 BDG's narrative, instead, draws significantly from critical development studies (e.g. Sachs,

4 1992; Latouche, 1993), including human (e.g. UNDP, 2004) and sustainable development

5 (e.g. Daly and Cobb, 1989; Wackernagel and Rees, 1996). These traditions of thought

6 developed a critique of the capitalist and neo-liberal regime, which explicitly includes intra-

7 and intergenerational justice and is taken up in the BDG's narrative.

8

18 Furthermore, the household is the level at which it is possible to work on the personal ethics

19 dimension that is so central in BDG, and is linked to the process of liberation from the desires

20 imposed by the consumer culture. Not surprisingly, therefore, it is in the household that

21 BDG's tool for monitoring and learning, i.e. the monthly budgets, are mostly used. The

22 collective dimension, being shaped by the local and national networks, as well as by the

23 cooperation with other actors of the alternative or sustainable lifestyle arena, plays an

24 important role in the BDG's internal learning and identification dynamics, but it is the

25 household that takes centre stage. 
TMI's narrative, instead, privileges the local communities as agents of change, being

2 it based on the challenge of resilience at local level. While TMI also place value on the

3 process of inner transition to accompany the collective process of change (Hopkins, 2011),

4 this is presented only as one component within a framework which locates the engine of

5 change within the community. Consequently, the TMI's narrative stresses the social

6 dimension of the learning process which, while coupled with individual change (inner

7 transition), is a driver of innovation in the communities and is pursued both online (e.g.

8 websites, blogs) and off-line (workshops).

$10 \quad 6.3$ Actions

\section{Active citizenship}

Both the BDG's and TMI's narratives are based on the idea that active citizenship, in

13 different forms, e.g. from activism to political participation or consumption choices, can and

14 should influence other actors, namely economic and political ones. The latter are perceived to

15 have largely set the values, rules and practices defining the current model of development,

16 and to be unable and unwilling to change quickly and deeply enough (Gesualdi, 2009;

17 Hopkins, 2011). Thus in both narratives, a defining moment is marked by citizens actively

18 taking responsibility for transformation, which results in the creation of niches for the

19 experimentation of innovation.

\section{Exemplary grassroot innovation}

Both BDG and TMI perceive themselves as positive examples, i.e. one which proves

23 that a system reconfiguration is possible, and is more successful in terms of meeting

24 environmental, social and economic objectives than current socio-technical regimes. The

25 narrative not only plays a role in the GI's morphogenesis, but the latter, widely narrated 
Feola, G. 2014. Narratives of grassroots innovations: A comparison of Voluntary Simplicity and the Transition Movement in Italy. International Journal of Innovation and Sustainable Development, 8(3):250-269. DOI: 10.1504/IJISD.2014.066612

1 through different traditional and new media, reinforces and reproduces the narrative of

2 change. For instance, the transition timeline (Chamberlin, 2009) is largely based on the idea

3 of developing a narrative that explains not only how the environmental crisis came to be, but

4 also generates new scenarios of alternative futures, which may inspire other local

5 communities to think differently about their future. The annual reports issued by BDG can be

6 seen to exert a similar function. They present the number of members, the activities carried

7 out, the change in consumption patterns and lifestyle choices, and compare these with

8 average national statistical values, thus giving a measure of actual change, as well as of

9 potential impact should lifestyle changes be more widely adopted (e.g. BDG, 2007). As for

10 the TMI, the annual reports reinforce the idea that alternative, innovative actions can be

11 successfully implemented, and illustrate how this can occur.

The actions undertaken by both BDG and TMI also show similarities. First, both

13 BDG and TMI local initiatives tend to address the same key themes of food, energy,

14 transport, housing, health and the organization of time. The types of initiatives developed

15 within the two GI are also rather similar and include local currencies, self- or co-production

16 of goods or energy, exchange of goods (e.g. food) and services (e.g. hospitality) (Gaggioli

17 and Valer, 2011; Hopkins, 2011).

\section{Opposition and collaboration}

While households and communities can innovate by creating alternative systems of

21 provision that lie outside the formal economy, they also aim to influence other actors

22 indirectly, i.e. through the market mechanisms (BDG, Gesualdi, 2009) or through political

23 representation, making ineligible policies eligible (TMI, Hopkins, 2011). However, BDG and

24 TMI differ in that the latter pursues engagement with local authorities and businesses, which

25 is one of the 12 steps of transition (Brangwyn and Hopkins, 2008). In order to facilitate such 
1 engagement, the Transition Initiatives Primer (Brangwyn and Hopkins, 2008) recommends

2 that the local transition initiatives take a recognised legal form, such as an unincorporated

3 association, or a charitable incorporated organization. The case of Monteveglio, the town

4 which is TMI's national hub, and whose council is strongly supportive and involved in the

5 transition initiatives, is often cited internationally as an example (Hopkins, 2011). The fact

6 that TMI's narrative identifies communities as agents of change, is likely to favour building

7 institutional partnerships and collaborations at the local level. Firstly, community groups,

8 better than households, can play the role of official interlocutors of institutions. Secondly, by

9 stressing the role of the community in building resilience, TMI is more inclined to include all

10 the actors in the local context into the "collective design process" (Hopkins, 2011: 45) of a

11 resilient community.

\section{Formalization}

While both networks maintain a light organization which guarantees their bottom-up

15 nature, TMI is overall more formalised than BDG. In particular, the national and the TN

16 international hubs retain a major role of coordination, training, production of communication

17 and information materials, and branding. This rather formalised set of norms and criteria

18 imposes a degree of management that is significantly higher than the one observed for BDG.

\section{Discussion}

21 The previous sections showed that BDG and TMI generate and continuously

22 reproduce their own narratives that connect analysis of world states, actors and actions of

23 change for the transformation of those world states. Despite several similarities, the BDG and

24 TMI's narratives differ substantially from each other and inform two internally consistent but 
Feola, G. 2014. Narratives of grassroots innovations: A comparison of Voluntary Simplicity and the Transition Movement in Italy. International Journal of Innovation and Sustainable Development, 8(3):250-269. DOI: 10.1504/IJISD.2014.066612

1 different configurations of internal structure and form of action and interaction with other

2 actors.

This section discusses in particular this study's fourth driving question in order to

4 uncover the two different ways the two GI empower niche innovation and what this implies

5 for the current and expected transition pathways the GI might undergo.

\subsection{Empowering innovation}

Both BDG and TMI are innovative niches that aim at empowering innovation to

9 "stretch and transform" (Smith and Raven, 2012) socio-technical regimes (e.g. food systems,

10 transport, energy production), i.e. to institutionalize new norms and practices that aim to

11 challenge and modify the regime, and to envision how actors can bring about transformations

12 of socially, environmentally, ethically undesirable world states (Franzosi, 1998). They claim

13 to represent realistic alternatives to malfunctioning socio-technical regimes which are deemed

14 to fail due to their own impact on the natural and social environment. They also aim to create

15 the capability and foster the creativity for innovation through encouraging active participation

16 (e.g. in regular meetings, workshops, annual events), usually in local small-group settings.

17 Such spaces are in themselves locations for debate over the institutions that regulate socio-

18 technical regimes and alternative to them (Smith and Raven, 2012).

19 Both BDG and TMI use narratives as tools to mobilize resources (e.g. funding) and

20 collective action (e.g. participants, local initiatives), and to counter the narrative of other,

21 possibly more powerful actors in the regime which may frame resilience and sustainability in

22 different fashions (Smith and Raven, 2012).

23 Thus, BDG and TMI take similar stands in the way they use narratives to create

24 positive expectations about the future and to make claims about present-day institutional

25 reforms. Regarding the former, it is apparent the use of narratives to make sense of world 
1 states (e.g. resource use and sustainability, climate change, social wellbeing) and create an

2 identity reinforced by a new vocabulary (e.g. "peak oil"). This contributes to the creation of

3 meaning for individuals in their local communities (Ruggiero, 2000). The narratives create

4 positive expectations and a visions about the future, for example envisioning a juster and

5 happier society, and identify the "possibility space" (Smith et al, 2005; Smith and Raven,

6 2012). Interestingly, the possibility space is, for both BDG and TMI but more explicitly for

7 the latter, left undefined and open to the results of emergent innovative and creative processes

8 that cannot be managed in a conventional sense (Kemp and Martens, 2007).

9 Regarding the use of narratives to make claims about insitutional reforms, both BDG

10 and TMI present themselves as alternative, realistic solutions to regimes that are not

11 sustainable and undergoing a crisis (see also Haxeltine and Seyfang, 2009). As observed in

12 other cases of niche innovation (Smith and Raven, 2012), in making their claims both BDG

13 and TMI frame their identity and strategies within broader landscape trends such as the

14 economic crisis, climate change or the growing prices of natural resources, which would open

15 windows of opportunity, and exert a top-down pressure on the regime that converges with the

16 bottom-up one exerted by the niche, whereby a transition to sustainability is potentially more

17 likely to occur.

18 Regarding the third theme of "stretch and transform" empowering niches, i.e. the

19 challenge to the regime, the narrative analysis has shown three significant differences

20 between BDG and TMI.

21 Firstly, regarding world states, BDG, as the name itself suggests, strongly emphasises

22 the ethical dimension of alternative lifestyles, whereas this, although partly present, is not a

23 pillar of TMI's narrative. This difference is apparent in several other elements of the

24 respective narratives, such as referring to either sustainability (BDG) or resilience (TMI). The

25 importance of justice in BDG's identity contributes to its higher complexity, whereby several 
1 dimensions (ethics, environment, quality of life), levels (individual, household, social) and

2 geographical poles (global justice in the North and South) articulate the causal relationships

3 that constitute the critique of the regime, and profile plausible alternatives. TMI's narrative

4 refers more strongly than BDG's to landscape trends (climate change, economic crisis) to

5 argue for the need for change in the regime, while BDG's narrative tends to critique more

6 directly the internal contradictions, and injustice of the regime structures. BDG's focus on

7 the household as principal agent of change seems to be consistent with such an emphasis on

8 the ethical dimension of everyday consumption and lifestyle choices, which are mainly

9 reproduced at this level (Reid et al, 2009). The ethical dimension plays a pivotal role in the

10 GI's identity. BDG challenges different socio-technical regimes on an ethical basis and

11 challenges not only factual (e.g. limited natural resources), but the ethical contradictions (e.g.

12 unequal share of costs and benefits of energy or material consumption patterns). This restricts

13 the BDG's narrative interpretive flexibility, confers integrity to it, and therefore improves the

14 internal cohesion of the niche, and diminishes its availability to compromise with competing

15 external identities (e.g. other niches or actors). Overall, as observed for voluntary simplicity

16 movements more in general (Maniates, 2002; Alexander, 2011) BDG's narrative configures a

17 more antagonistic stand, which is more value laden than TMI, which, instead, configures a

18 more synergetic stand (Seyfang and Haxeltine, 2012). BDG's narrative thus supports the

19 reduction of consumption and which entails more radical forms of innovation than moving to

20 ethical or environmentally friendly goods and services, in that it deeply challenges the logic

21 of economic growth that underpins socio-technical regimes in the current growth based

22 economic systems.

A second difference between BDG and TMI with respect to their challenging socio-

24 technical regimes relates to the way the two networks are structured. Both GI are network-

25 based organization, with a global structure but local specificities, which is a common trait of 
Feola, G. 2014. Narratives of grassroots innovations: A comparison of Voluntary Simplicity and the Transition Movement in Italy. International Journal of Innovation and Sustainable Development, 8(3):250-269. DOI: 10.1504/IJISD.2014.066612

1 movements opposing neo-liberalism (e.g. Cumbers et al, 2008). However, despite both being

2 grassroots movements that encourage creativity, diversity and innovation, TMI operates in a

3 more structured and formal manner than BDG, i.e. as a canonical rather than a shadow system

4 (Pelling, 2007). As noted by Smith (2011) with reference to the British TM network, this

5 aspect has attracted some criticism for not being recognised by TM's members as sufficiently

6 manifesting an 'activist' nature, i.e. for constraining to some extent that very creativity. On

7 the other hand, the standardised organization favours the internal morphogenesis of the niche

8 in aspects such as the exchange of information within the network, the facilitation of more

9 effective learning processes through direct experience, the support of local nodes, the creation

10 of a stronger sense of belonging and identity (Feola and Nunes, 2014). Importantly, internal

11 standardization and formalization make the TMI compatible with the rules of engagement

12 with, and therefore visible to, actors in the socio-technical regimes (e.g. local authorities,

13 local energy or food businesses) which the TMI aims to influence.

14 This leads to a third important difference between BDG and TMI, which relates to

15 their actions, i.e. the strategy the GI as niches adopt in interacting with economic and

16 institutional actors. While BDG seems to tend towards alternative, or shadow (Pelling, 2007)

17 systems of provision, often outside the formal economy, TMI couples this strategy with a

18 canonical explicit and structural attempt to engage with other actors in the community that

19 can help build local resilience. In other words, TMI seems more prone to combine bottom-up

20 and top-down measures, but more exposed than BDG to the paradox of pursuing radical

21 innovation while at the same time proposing itself as compatible with socio-technical regimes

22 in order to be able to influence them (see Smith, 2005). These different strategies seem at

23 least partly linked to the weight attributed to justice within the TMI's narrative, and supported

24 by a specific type of organizational structure. As noted above, BDG's narrative seems to have

25 a lower degree of interpretive flexibility due to its hard core ethical dimension and its pursuit 
1 of innovative lifestyles that require a consumption reduction. It is therefore more difficult for

2 BDG to form coalitions for change with actors that do not share a similar ethical basis. In

3 comparison, TMI's narrative appears to be more flexible to interpretation (Seyfang and

4 Haxeltine, 2012), which can facilitate attracting new members into the niche, and the

5 synergetic process of forming coalitions for change with other actors from dominant socio-

6 technical regimes (e.g. small local businesses, local authorities). In effect not only

7 engagement with other actors, but also with other niches (e.g. other GI) is positively seen in

8 the TMI (Brangwyn and Hopkins, 2008), although this might be seen negatively, i.e. a form

9 of co-option between niches, by some members of those other GI (anonymous grassroots

10 activist, personal communication).

11

14 research. By looking at sheer numbers, TMI appears to be more successful in that it has

15 spread more rapidly than BDG and, despite being a much more recent movement, involves

16 more people. Such a rapid diffusion, similar to that observed in other countries, is perhaps

17 facilitated by the relatively simple narrative, which builds on themes such as climate change,

18 peak oil and the economic crisis, which are extremely topical landscape trends. In addition,

19 because of the minor weight attributed to the ethical dimension and the individual level, TMI

20 takes a more synergetic stand than BDG, and might require a less fundamental

21 reconsideration of lifestyles than BDG, i.e. it might involve less deep personal convictions

22 and values because it might be seen to shift the locus of control from the individual to the

23 community. On the other hand, it has been argued that the narrow basis, i.e. climate change

24 and peak oil, of TMI's narrative can work against widespread acceptance (Smith, 2011;

25 Wells, 2011). No less fundamentally, the TM's apolitical stand can be seen to reduce its 
1 potential because it does not address the causes of the problems to which it aims to respond,

2 and does not contend with the regime, e.g. on an ethical basis (Trapese, 2008; Seyfang and

3 Haxeltine, 2012). In comparison, a more articulated narrative and antagonistic, ethical stand,

4 such as that of BDG, can be expected to make a stronger basis for a normative

5 reconfiguration of socio-technical regimes (Pelling, 2011).

6 Furthermore, it could be hypothesised that TMI's comparatively heavier

7 organizational structure not only facilitates the mobilization of resources, but also puts TMI

8 in a more influential position to interact with actors in dominant socio-technical regimes, or

9 to develop alternative systems of provision outside the formal economy. However, it has been

10 argued that such an organizational approach might bring the transition initiatives into the

11 mainstream and become like other third sector groups (Smith, 2011). In other words, that this

12 approach might promote innovations that fit and conform with socio-technical regimes, rather

13 than stretch and transform them (Smith and Raven, 2012). Moreover, the partnership with

14 business and institutional actors poses the risk "that politics and issues of co-option into co-

15 production take centre stage, further diverging the movement from its core rhetoric" (Smith,

16 2011, page 102, see also Seyfang and Smith, 2007; Wells, 2011). Thus, while TMI's narrative

17 builds on the idea of innovative substitution (of the regime with the niche), there is the actual

18 risk that the observed transition pattern is that of a weak co-option (of the niche by the

19 regime) instead (Geels and Shot, 2007; Haxeltine and Seyfang, 2009).

\subsection{Limitations of the study}

Finally, it is also important to note the limitations of the comparative narrative

23 analysis adopted in this study. First, narratives are only one of the factors that influence the

24 interactions between niches and regimes, with e.g. power and technological structures, and

25 resources also potentially playing a fundamental role. Second, this study focussed on the GI's 
1 narratives but did not investigate how this is taken and elaborated by actors in selected socio-

2 technical regimes. Narrative re-elaboration by external actors is potentially a mechanism

3 through which GI are co-opted and the transformative potential of their innovation reduced,

4 but this was out of the scope of this study and would have required a different methodological

5 approach. Finally, this study provides a cross sectional analysis, i.e. of how the GI's

6 narratives influence their identity, internal structure and forms of action and external

7 interaction, but does not consider how the narrative influenced the GI's development in time,

8 either internally or in relation with the regime and landscape level. All of these points

9 represent potentially fruitful avenues for future research.

\section{Conclusions}

This paper originated by the need for understanding narratives and the role they can

13 play in empowering innovation towards sustainability and resilience. The paper focussed on

14 how the narratives respectively influence the internal GI's identity, structure, form of action,

15 and their interactions with other actors. It showed that despite some commonalities, BDG's

16 and TMI's narratives differ significantly, in particular for the weight attributed to global

17 justice and to sustainability or resilience goals, the identified actors of change (households

18 and communities), the complexity of the narrative itself, and the degree of oppositional stand.

19 It also showed that these narratives underpin different internally consistent organizational

20 forms and strategies of interaction with the GI's external actors. By and large, TMI seems to

21 be more synergetic than BDG, i.e. to pursue a degree of compatibility with, while at the same

22 time aiming at radical change of, socio-technical regimes. Thus, while both BDG and TMI

23 employ narratives to institutionalize norms and institutions and to mobilize resources and

24 human capital, they differ in how they challenge existing socio-technical regimes. It can be

25 therefore hypothesized that the two GI are exposed to a different degree to the potential to 
1 transform incumbent regimes through innovation, and risks of innovations being co-opted by

2 regime actors. Further research is needed to shed light onto the dynamic process of challenge

3 to selected socio-technical regimes. This research could include on the one hand, how the

4 GI's narrative develop over time under changes at the regime and landscape level and, on the

5 other, how actors in incumbent regimes re-elaborate the GI's narratives to respond to the

6 challenge posed by innovative niches.

\section{Acknowledgements}

9 The author thanks Steve Musson and Sophie Bowlby for their use-ful comments on a

10 previous ver-sion of this manuscript. This pa-per is a revised and expanded version of a paper

11 entitled 'Vol-untary simplicity and Transition Network: a comparison of narra-tives, practices

12 and strategies' presented at 18th Annual Inter-national Sustainable Develop-ment Research

13 Conference, Uni-versity of Hull, United Kingdom, 24-26 June 2012.

\section{References}

16 Abell, P. (2004) "Narrative Explanation: An Alternative to Variable-Centered Explanation?"

$17 \quad$ Annual Review of Sociology 30 287-310

18 Alexander, S. (2011) Property Beyond Growth. Toward a Politics of Voluntary Simplicity,

19 PhD thesis, Faculty of Law, University of Melbourne

20 Bilanci di Giustizia (BDG), 2007, Rapporto annuale 2007 [online]. Available from:

21 http://www.bilancidigiustizia.it/index.php? module=Pagesetter\&func=viewpub\&tid=14\&pid

$22 \quad=5$ [Accessed April 2012] 
1 Bilanci di Giustizia (BDG), 2009, Rapporto annuale 2009 [online]. Available from:

2 http://www.bilancidigiustizia.it/index.php?module=Pagesetter\&func=viewpub\&tid=14\&pid

$3 \quad \underline{=8}$ [Accessed April 2012]

4 Bergman, N., Markusson, N., Connor, P., Middlemiss, L., and Ricci, M. (2010) "Bottom-up,

5 social innovation for addressing climate change", in Energy transitions in an interdependent

6 world: what and where are the future social science research agendas, 25-26 February

$7 \quad 2010$, Sussex

8 Bologna, G., Gesualdi, F., Piazza, F., and Saroldi, A. (2000) Invito alla sobrieta felice (EMI,

9 Bologna)

10 Boyce, M.E. (1996) "Organizational story and storytelling: a critical review" Journal of

11 Organizational Change Management 9 5-26

12 Brangwyn, B., and Hopkins, R., 2008. Transition Initiatives Primer [online]. Available from:

13 http://www.transitionnetwork.org/sites/default/files/TransitionInitiativesPrimer\%283\%29.pd

$14 \quad \underline{f}$ [Accessed April 2012]

15 Brown, A.D., and Rhodes, C. (2005) "Narrative, organizations and research" International

16 Journal of Management Reviews 7 167-188

17 Chamberlin, S. (2009) The Transition Timeline. (Green Books, Totnes)

18 Corbetta, P. (1999) Metodologia e tecniche della ricerca sociale (Il Mulino, Bologna)

19 Cumbers, A., Routledge, P., and Nativel, C. (2008) "The entangled geographies of global

20 justice networks" Progress in Human Geography 32 183-201 
1 Dahle, K. (2007) "When do transformative initiatives really transform? A typology of

2 different paths for transition to a sustainable society" Futures 39 487-504

3 Daly, H., and Cobb, J. (1989) For the Common Good (Beacon Press, Boston)

4 Doherty, D., and Etzioni, A. (2003) Voluntary simplicity: responding to consumer culture $5 \quad$ (Rowman and Littlefield Publishers, Lanham)

6 Elgin, D, Mitchell, A. (1977) “Voluntary Simplicity” Co-Evolution Quarterly

7 Elgin, D. (1981) Voluntary simplicity: toward a way of life that is outwardly simple, inwardly $8 \quad$ rich (Quill, New York)

9 Etzioni, A. (1998) "Voluntary Simplicity: Characterization, Select Psychological 10 Implications, and Societal Consequences” Journal of Economic Psychology 19 619-643

11 Feola, G., and Nunes, J.R. (2014) "Success and failure of Grassroots Innovations for 12 addressing climate change: the case of the Transition Movement" Global Environmental $13 \quad$ Change $24232-250$

14 Franzosi, R. (1998) "Narrative Analysis. Or Why (And How) Sociologists Should Be 15 Interested In Narrative" Annual Review of Sociology 24 517-544

16 Gaggioli, L., and Valer, A. (2011), Prove di felicita quotidiana (Terre di Mezzo Editore, 17 Milan)

18 Geels, F., and Schot, J. (2007) "Typology of sociotechnical transition pathways" Research 19 Policy 36 399-417

20 Gesualdi, F. (2009), The other way. A new society in a slow economy [online] Centre for a 21 New Model of Development. Available from: 
1 http://www.cnms.it/sites/default/files/The\%20\%200ther\%20Way_0.pdf [Accessed April

2 2012]

3 Gunderson, L. and Holling, C.S. (2001) Panarchy. Understanding Transformations in Human

4 and Natural Systems (Island Press, London)

5 Hargreaves, T., Haxeltine, A., Longhurst, N., and Seyfang, G. (2011) Sustainability transition

6 from the bottom-up: Civil society, the multilevel perspective and practice theory, CSERGE

$7 \quad$ Working Paper 2011-01

8 Haxeltine, A., and Seyfang, G. (2009) Transitions for the People: Theory and Practice of

9 ,Transition ' and, Resilience“ in the UK's Transition Movement. Working Paper 134, Tyndall

10 Centre for Climate Change Research

11 Holmgren, D. (2003) Permaculture: Principles and pathways beyond sustainability

12 (Holmgren Design Press)

13 Hopkins, R. (2009) Transition to a world without oil, TED Global Conference, Oxford

14 Hopkins, R. (2011) The Transition Companion (Green Books, Totnes)

15 Intergovernmental Panel on Climate Change (IPCC) (2013) "Working Group I. Contribution

16 to the IPCC Fifth Assessment Report. Climate Change 2013: The Physical Science Basis.

17 Summary for Policymakers“ (IPCC, Geneva)

18 Jackson, T. (2009) Prosperity without growth (Earthscan, London)

19 Kemp, R., and Martens, P. (2007) ,Sustainable development: how to manage something that

20 is subjective and never can be achieved?' Sustainability: Science, Practice, \& Policy 35-14 
1 Kennedy, E. H. (2011) "Rethinking ecological citizenship: the role of neighbourhood networks in cultural change" Environmental Politics 20 843-860

3 Latouche, S. (1993) In the Wake of the Affluent Society: An Exploration of Post-Development $4 \quad$ (Zed Books, London)

5 Maniates, M. (2002) "In Search of Consumptive Resistance: The Voluntary Simplicity

6 Movement", in T Princen, M Maniates, K Conca, Confronting Consumption (MIT Press, 7 Cambridge)

8 Martínez-Alier, J., Pascual, U., Vivien, F-D., and Zaccai, E. (2010) "Sustainable de-growth:

9 Mapping the context, criticisms and future prospects of an emergent paradigm" Ecological $10 \quad$ Economics 69 1741-1747

11 Maturana, H. R., and Varela, F. J. (1992) The tree of knowledge: The biological roots of 12 human understanding (Shambhala, Boston)

13 Meadows, D., Meadows, D., and Randers, J. (2005) Limits to Growth. The 30-Year Update 14 (Earthscan, London)

15 Melucci, A. (1985) “The Symbolic Challenge of Contemporary Movements” Social Research $16 \quad \mathbf{5 2} 789-815$

17 Moulaert, F., Martinelli, F., Swyngedouw, E., and Gonzalez, S. (2005) "Towards Alternative 18 Model(s) of Local Innovation” Urban Studies 421969 -1990

19 Mulugetta, Y., Jackson, T., and van der Horst, D. (2010) "Carbon reduction at community scale" Energy Policy 38 7541-7545 
1 O’Brien, K. (2011) “Global environmental change II: From adaptation to deliberate

2 transformation" Progress in Human Geography. In press.

3 Pelling, M., High, C., Dearing, J., and Smith, D. (2007) “Shadow Spaces for Social Learning:

4 A Relational Understanding of Adaptive Capacity to Climate Change within Organizations"

$5 \quad$ Environment and Planning A 40 867-884

6 Pelling, M. (2011) Adaptation to Climate Change. From Resilience to Transformation $7 \quad$ (Routledge, London)

8 Rappaport, J. (2000) "Community narratives: Tales of terror and joy" American Journal of $9 \quad$ Community Psychology 28 1-24

10 Reid, L., Sutton, P., and Hunter, C. (2009) "Theorizing the meso level: the household as a

11 crucible of pro-environmental behaviour" Progress in Human Geography 34 309-327

12 Riley, T., and Hawe, P. (2005) "Researching practice: the methodological case for narrative 13 inquiry" Health Educational Research 20 226-236

14 Rotmans, J., Kemp, R., and van Asselt, M. (2001) "More evolution than revolution: transition 15 management in public policy" Foresight 3 1-17

16 Ruggiero, V. (2000) Movimenti nella citta (Bollati Boringhieri, Turin)

17 Sachs, W. (1992) The Development Dictionary: A Guide to Knowledge as Power (Zed Books, 18 London)

19 Scott-Cato, M., and Hillier, J. (2010) "How could we study climate-related social innovation? 20 Applying Deleuzean philosophy to Transition Towns" Environmental Politics 19 869-887 
1 Seyfang, G., and Smith, A. (2007) “Grassroots innovations for sustainable development:

2 Towards a new research and policy agenda" Environmental Politics 16 584-603

3 Seyfang, G., and Haxeltine, A. (2012) "Growing grassroots innovations: exploring the role of

4 community-based initiatives in governing sustainable energy transitions" Environment and

$5 \quad$ Planning C: Government and Policy 30 381-400

6 Seyfang, G., Haxeltine, A., Hargreaves, T., and Longhurst, N. (2010) Energy and communities

7 in transition - towards a new research agenda on agency and civil society in sustainability

8 transitions, CSERGE Working Paper No. EDM 10-13

9 Shaw, D., and Newholm, T. (2002) "Voluntary Simplicity and the Ethics of Consumption" $10 \quad$ Psychology and Marketing 19 167-185

11 Schot, J., and Geels, F. W. (2008) "Strategic niche management and sustainable innovation

12 journeys: theory, findings, research agenda, and policy” Technology Analysis \& Strategic

$13 \quad$ Management 20 537-554

14 Smith, A. (2005) "Green niches in sustainable development: the case of organic food in the

15 United Kingdom" Environment and Planning C: Government and Policy 24 439-458

16 Smith, A. (2011) “The Transition Town Network: A Review of Current Evolutions and

17 Renaissance” Social Movement Studies 10 99-105

18 Smith, A., and Raven, B. (2012), „What is protective space? Reconsidering niches in

19 transition to sustainability“ Research Policy 41 1025-1036

20 Smith, A., Stirling, A., and Berkhout, F. (2005) "The governance of sustainable socio-

21 technical transitions" Research Policy 34 1491-1510 
1 Snow, D. A., Burke, R. E., Worden, S. K., and Benford, R. D. (1986) "Frame aligment

2 processes, micromobilization, and movement participation" American Sociological Review

$3 \mathbf{5 1} 464-481$

4 Stuber, S. C. (2000) "The interposition of personal life stories and community narratives in a

$5 \quad$ Roman Catholic religious community” Journal of Community Psychology 28 507-515

6 Sztompka, P. (1993) The Sociology of Social Change (Wiley-Blackwell, Oxford)

7 Trapese (2008) The rocky road to a real transition: The Transition Towns Movement and what

8 it means for social change, Trapese Popular Education Collective

9 Wackernagel, M., and Rees, W. (1996) Our Ecological Footprint: Reducing Human Impact 10 on the Earth (New Society Publishers, Gabriola Island)

11 Walker, G. (2011) “The role for "community" in carbon governance" Wiley Interdisciplinary

12 Reviews: Climate Change 2 777-782

13 German Advisory Council on Global Change (WBGU) (2011) "World in Transition. A Social

14 Contract for Sustainability" (WBGU, Berlin)

15 Wells, P. (2011) "The transition initiative as a grass-roots environmental movement: history, 16 present realities and future predictions" Interdisciplinary Environmental Review 12 372-386

17 Wiek, A., Ness, B., Schweizer-Ries, P., Brand, F., and Farioli, F. (2012) "From complex 18 systems analysis to transformational change: a comparative appraisal of sustainability science projects" Sustainability Science 7 5-24 
Table 1. Comparison of BDG and TMI's narratives

\begin{tabular}{|c|c|c|}
\hline & BDG & TMI \\
\hline \multirow[t]{3}{*}{ World states } & \multicolumn{2}{|c|}{ Environmental crisis and poor social wellbeing } \\
\hline & Justice & - \\
\hline & Sustainability & Resilience \\
\hline Actors & Networked households & Networked communities \\
\hline \multirow[t]{4}{*}{ Actions } & \multicolumn{2}{|c|}{ Active citizenship } \\
\hline & \multicolumn{2}{|c|}{ Exemplary grassroots innovations } \\
\hline & Opposition & Collaboration \\
\hline & - & Formalization \\
\hline
\end{tabular}

